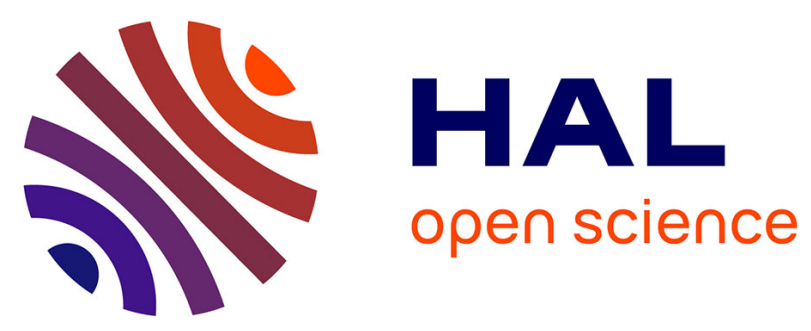

\title{
Influence of the p-type doping on the radiometric performances of MWIR InAs/GaSb superlattice photodiodes
}

E. Giard, I. Ribet-Mohamed, M. Delmas, J.B. Rodriguez, Philippe Christol

\section{- To cite this version:}

E. Giard, I. Ribet-Mohamed, M. Delmas, J.B. Rodriguez, Philippe Christol. Influence of the p-type doping on the radiometric performances of MWIR InAs/GaSb superlattice photodiodes. QSIP, Jun 2014, SANTA FE, United States. hal-01070571

\section{HAL Id: hal-01070571 \\ https://hal-onera.archives-ouvertes.fr/hal-01070571}

Submitted on 1 Oct 2014

HAL is a multi-disciplinary open access archive for the deposit and dissemination of scientific research documents, whether they are published or not. The documents may come from teaching and research institutions in France or abroad, or from public or private research centers.
L'archive ouverte pluridisciplinaire HAL, est destinée au dépôt et à la diffusion de documents scientifiques de niveau recherche, publiés ou non, émanant des établissements d'enseignement et de recherche français ou étrangers, des laboratoires publics ou privés. 


\title{
Influence of the p-type doping on the radiometric performances
}

of MWIR InAs/GaSb superlattice photodiodes.

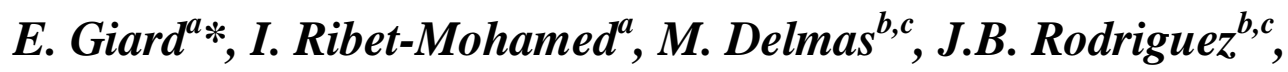 \\ P. Christol ${ }^{b, c}$ \\ ${ }^{a}$ ONERA, Chemin de la Hunière, 91761 Palaiseau- France \\ ${ }^{b}$ Univ. Montpellier, IES, UMR 5214, F-34000, Montpellier, France \\ ${ }^{c}$ CNRS, IES, UMR 5214, F-34000, Montpellier, France
}

\begin{abstract}
In this paper, quantum efficiency (QE) measurements performed on type-II InAs/GaSb superlattice (T2SL) photodiodes operating in the mid-wavelength infrared domain, are reported. Several comparisons were made in order to determine the SL structure showing optimum radiometric performances : same InAs-rich SL structure with different active zone thicknesses (from $0.5 \mu \mathrm{m}$ to $4 \mu \mathrm{m}$ ) and different active zone doping (n-type versus p-type), same $1 \mu \mathrm{m}$ thick p-type active zone doping with different SL designs (InAs-rich versus GaSbrich and symmetric SL structures). Best result was obtained for the p-type doped InAs-rich SL photodiode, with a $4 \mu \mathrm{m}$ active zone thickness, showing a $\mathrm{QE}$ that reaches $61 \%$ at $\lambda=2 \mu \mathrm{m}$ and $0 \mathrm{~V}$ bias voltage.
\end{abstract}

PACS 73.21.Cd, 73.40.Kp, 85.60.Bt, 80.60.Gz

Keyword: InAs/GaSb Superlattice, photodiode, Quantum efficiency.

*Corresponding author: Tel.: (+33) 180386 334;

e-mail address: edouard.giard@onera.fr 


\section{Introduction}

Type II InAs/GaSb superlattices (T2SL) were introduced in the early 70s by Esaki and Tsu [1]. T2SL mid-wavelength infrared (MWIR) pin photodiodes were first studied by Yang and Bennet in 1994 [2]. Since then, significant improvements were obtained on SL detectors as show demonstrations of high-performance MWIR focal plane arrays (FPA) [3-7]. These performances were obtained with devices designed with barriers [8-10] to reduce the generation recombination dark current. Another way to enhance performances is to reduce the Shockley-Read-Hall (SRH) recombination mechanism in order to increase the carrier lifetimes. Most T2SL devices exhibit shorter carrier lifetime than InAs/InAsSb superlattices [11]. But InAs/InAsSb superlattices have not yet reached the same performance than T2SL in terms of quantum efficiency (QE) and dark current [12].

Therefore to combine the long carrier lifetime of the InAs/InAsSb superlattice and the good QE of the T2SL, an InAs-rich T2SL was proposed [13]: this superlattice exhibits an InAs to $\mathrm{GaSb}$ thickness ratio close to $\mathrm{R}=2$. Good performances in terms of dark current were already reported [13-15] but a recent study tends to prove a problem of minority carrier collection with this design [16] leading to non-optimal performances in terms of QE.

In this paper, we report on quantum efficiency of MWIR SL photodiodes with active zone made of asymmetric period composed of 7 InAs monolayers (MLs) / 4 GaSb MLs (7/4 SL structure), showing cut-off wavelength at $5 \mu \mathrm{m}(77 \mathrm{~K})$. We study the influence of a p-type doping in the active zone in order to correct the non-optimal collection of the minority carriers. Then we study the influence of the InAs to GaSb thickness ratio on the radiometric performances of MWIR InAs/GaSb superlattice photodiodes. 


\section{Samples}

The InAs/GaSb SL structure for the MWIR domain was grown on p-type $\mathrm{GaSb}$ substrate by Molecular Beam Epitaxy. The growth procedure, the epitaxy characterization and the device processing were already reported [14]. The structure is described in Fig. 1: it consists of a $200 \mathrm{~nm}$ Be-doped (p+ type doping $\sim 1 \times 10^{18} \mathrm{~cm}^{-3}$ ) GaSb buffer layer, a $60 \mathrm{~nm} \mathrm{Be-}$ doped ( $\mathrm{p}+$ type doping $\sim 1 \times 10^{18} \mathrm{~cm}^{-3}$ ) SL layer, an InAs/GaSb SL active zone, a $60 \mathrm{~nm}$ Tedoped ( $\mathrm{n}+$ type doping $\sim 1 \times 10^{18} \mathrm{~cm}^{-3}$ ) SL layer, and a $20 \mathrm{~nm}$ Te-doped (n+-type doping $\sim 1 \times 10^{18} \mathrm{~cm}^{-3}$ ) InAs cap layer. Different samples are presented in this paper: the first samples (A, B, C) have an InAs-rich design with active layer thickness varying from 500nm (155 periods) to $4 \mu \mathrm{m}$ (1240 periods). The asymmetric period of this non-intentionally doped (nid) active zone is composed of 7 InAs monolayers (MLs) / 4 GaSb MLs (7/4 SL structure). Then the second set of samples contains two InAs-rich (7/4 SL structure) samples (D, E) with active layer thickness of $500 \mathrm{~nm}$ and $4 \mu \mathrm{m}$ respectively. But, unlike the first set of samples, the active zone of these samples is Be-doped ( $\mathrm{p}$ type doping $\sim 1 \times 10^{15} \mathrm{~cm}^{-3}$ ). The two last samples exhibit an active layer thickness equal to $1 \mu \mathrm{m}$ with two different designs: sample $\mathrm{F}$ is a GaSbrich (10/19) SL structure and sample B a symmetric (10/10) SL structure. These samples are listed in Table 1.

All these samples exhibit photoluminescence emission and cut-off wavelength around $5 \mu \mathrm{m}$ at $77 \mathrm{~K}$. From epitaxial SL material, circular mesa photodiodes were fabricated using standard photolithography. The devices were placed in a $\mathrm{LN}_{2}$ bath cryostat ready to perform photoelectrical measurements at $77 \mathrm{~K}$. All measurements presented below were performed with a front side illumination (through the InAs cap layer) on $160 \mu \mathrm{m}$ diameter photodiodes. 


\section{Influence of the active zone thickness on the QE spectrum for InAs-rich T2SL pin photodiodes}

To investigate an eventual non-optimal collection of the minority carriers suspected [16] in the InAs-rich SL structure, we decided to measure QE spectra of several InAs-rich samples with different active zone thicknesses (AZT). Fig. 2 presents the QE spectra of three InAs-rich samples with different nid AZT: 500nm (sample A), $1 \mu \mathrm{m}$ (sample B) and $4 \mu \mathrm{m}$ (sample C). The QE spectra were measured at $77 \mathrm{~K}$ and $0 \mathrm{~V}$ bias voltage.

Each QE spectrum was measured in two steps. First the relative photoresponse was measured using a FTIR spectrometer and then the absolute QE was calibrated using a SR200 blackbody [16].

The following comments can be made on Fig. 2: at $0 \mathrm{~V}$ bias voltage, the QE between $\lambda$ $=4.5 \mu \mathrm{m}$ and $\lambda=5 \mu \mathrm{m}$ doesn't depend on the thickness of the active layer. However, at $0 \mathrm{~V}$ bias voltage for shorter wavelengths, the thinner the active zone is, the higher the QE is. In the inset of Fig. 2 are plotted the experimental QE of the same samples at $\lambda=4.5 \mu \mathrm{m}$ versus the electric field, calculated as the ratio between the bias voltage and the active zone thickness. The $\mathrm{QE}$ of the thinnest active zone presents no bias voltage dependence. The $\mathrm{QE}$ of the $1 \mu \mathrm{m}$ thick active zone increases with the reverse bias voltage until $-10000 \mathrm{~V} / \mathrm{cm}\left(\mathrm{U}_{\text {bias }}=-1 \mathrm{~V}\right)$, and is constant for high reverse bias voltages. The $\mathrm{QE}$ of the thickest active zone increases linearly also with the reverse bias voltage. This reverse bias dependence of the QE could be the signature of a non-optimal minority carrier collection. Indeed, the nid region of the InAs-rich SL structures is expected to be n-type residual at $77 \mathrm{~K}$, therefore the minority carriers are the holes. The real P-N junction is between the active layer and the p+-doped SL layer, "far" from the illuminated side which is the InAs cap layer. The space charge region (SCR) width was calculated with the Poisson's equations equal to $451 \mathrm{~nm}$ for $0 \mathrm{~V}$ bias voltage. The $500 \mathrm{~nm}$ thick active zone is quite completely depleted at $0 \mathrm{~V}$ whereas the $1 \mu \mathrm{m}$ thick active zone and the $4 \mu \mathrm{m}$ 
thick active zone are not. Therefore, the bias dependence of the QE (see the inset of Fig. 2) and the low QE values at OV bias voltage for short wavelengths and thick structures (see Fig. 2) can be explained by a short hole diffusion length. The hole diffusion length is necessarily shorter than $500 \mathrm{~nm}$ because the $1 \mu \mathrm{m}$ thick active zone is not completely depleted at $0 \mathrm{~V}$ and the QE of this device increases linearly until $-10000 \mathrm{~V} / \mathrm{cm}$.

\section{Influence of the p-type doping on the QE spectrum of InAs-rich T2SL photodiodes.}

To optimize the minority carrier collection, we decided to dope the active zone with Beryllium ( $\mathrm{p}$-type doping $\sim 5 \times 10^{15} \mathrm{~cm}^{-3}$ ). Be-doping was already used to increase the performances of InAs-rich structure but only in the long-wavelength infrared (LWIR) domain [17]. In the Be-doped active zone, the minority carriers are the electrons, unlike in the nid active zone in which the minority carriers are the holes (n-type residual doping). Because the electron mobility is higher than the hole mobility, the electron diffusion length is expected to be longer than the hole diffusion length.

Fig. 3 presents the QE spectrum of sample D at $0 \mathrm{~V}$ bias voltage and $77 \mathrm{~K}$ operating temperature. Sample D has a p- doped active zone and its active zone thickness is equal to $4 \mu \mathrm{m}$. Sample D was compared to sample $\mathrm{C}$ which has the same active zone thickness and the same 7/4 design but its active zone is nid. The QE of $\mathrm{p}$ doped active zone is higher than the $\mathrm{QE}$ of the nid active zone in the entire spectrum. The QE reaches $61 \%$ at $\lambda=2 \mu \mathrm{m}$. In the $\mathrm{p}$ doped active zone, nearly all photo-generated carriers are collected, whereas, in the nid active zone, carriers which are photo-generated far from the SCR are not collected. The inset of Fig. 3 presents the experimental $\mathrm{QE}$ of samples $\mathrm{C}$ and $\mathrm{D}$ at $\lambda=4.5 \mu \mathrm{m}$ versus the bias voltage. For reverse bias voltages higher than $-0.4 \mathrm{~V}$, the $\mathrm{QE}$ of sample $\mathrm{D}$ is nearly constant. It means that the electron diffusion length is long enough to collect nearly all minority carriers. But it also 
means that the electron diffusion length is shorter than $4 \mu \mathrm{m}$ because between $0 \mathrm{~V}$ and $-0.4 \mathrm{~V}$ the $\mathrm{QE}$ increases with the reverse bias voltage.

\section{Influence of the SL design on the QE spectrum of T2SL photodiodes.}

To study the influence of the InAs to GaSb thickness ratio on the radiometric performances of MWIR InAs/GaSb superlattice photodiodes, two other samples were grown with different designs: sample F exhibits a GaSb-rich design (10/19 SL structure) and sample G exhibits a symmetric design (10/10 SL structure). These two samples have a $1 \mu \mathrm{m}$ thick active layer. Therefore we can compare these samples with sample B but not with sample D which is thicker.

That's why we decided to interpolate the QE spectrum of a $1 \mu \mathrm{m}$ thick p-doped active zone. We used the Hovel's expression [18] where the total QE is the sum of three contributions:

$$
Q E=Q E_{S C R}+Q E_{n}+Q E_{p}
$$

where $\mathrm{QE}_{\mathrm{SCR}}$ is the contribution of the space charge region, $\mathrm{QE}_{\mathrm{n}}$ is the contribution from the quasineutral $\mathrm{n}$ region and $\mathrm{QE}_{\mathrm{p}}$ is the contribution from the quasineutral $\mathrm{p}$ region. The contribution from the quasineutral $\mathrm{n}$ region is negligible because that layer is thin and has a low hole mobility therefore $\mathrm{QE}_{\mathrm{n}} \approx 0$.

$$
\begin{aligned}
& \mathrm{QE}_{S C R}=(1-R) \times\left(e^{-\alpha x_{n}}-e^{-\alpha x_{p}}\right) \\
& \mathrm{QE}_{p}=(1-R) \frac{\alpha L_{n}}{\left(\alpha L_{n}\right)^{2}-1} e^{-\alpha x_{p}}\left(\alpha L_{n}-\frac{\sinh \left(\frac{W}{L_{n}}\right)+\alpha L_{n} e^{-\alpha W}}{\cosh \left(\frac{W}{L_{n}}\right)}\right)
\end{aligned}
$$

where $\mathrm{R}$ is the reflectivity of the top surface, $\alpha$ is the absorption coefficient, $\mathrm{x}_{\mathrm{n}}$ and $\mathrm{x}_{\mathrm{p}}$ are the $\mathrm{n}$ and $\mathrm{p}$ depletion regions, $\mathrm{W}$ is the SCR width and $\mathrm{L}_{\mathrm{n}}$ is the electron diffusion length. $\alpha$ is proportional to the density of states. A realistic hypothesis for the InAs-rich structure is a quasi 3D density of states owing to the large electron-holes wave-function overlap [14]. Therefore $\alpha$ was taken proportional to the square root of the energy. 
Only the shape of the curve was simulated by these equations: therefore to simplify the model, the surface recombination velocity was set equal to zero. Then the relative magnitudes were calibrated using the experimental data of samples D and E. Sample E has a 500nm thick p-doped active zone. Fig. 4 presents the calibration of the simulated QE for these two samples and the interpolation of the QE for a $1 \mu \mathrm{m}$ thick p-doped active zone. This interpolation was also reported in Fig. 5 where a comparison between this simulated p-doped InAs-rich spectrum and three experimental QE spectra (samples B, F, G) of T2SL photodiodes with $1 \mu \mathrm{m}$ thick active zone was made. The three samples present different design: sample $\mathrm{F}$ is GaSbrich, $\mathrm{G}$ is symmetric and B is InAs-rich and its active zone is n type residual. The last curve is the QE simulated for a $\mathrm{p}$ doped InAs-rich active zone. The p-doped InAs-rich active zone exhibits higher QE than the GaSb-rich and the symmetric active zones in the entire spectrum. This result confirms what was expected [13], that the InAs-rich design is more efficient than the symmetric and the GaSb designs. The absorption is better in the InAs-rich design because of its large electron-holes wave-function overlap.

\section{Conclusion}

QE were measured on T2SL test photodiodes, with different AZT or different SL designs, with or without Be-doping in the active zone. The highest QE at $0 \mathrm{~V}$ bias voltage was obtained with an InAs-rich 7/4 SL structure with a p-type doped active zone. For this structure, with a $4 \mu \mathrm{m}$ thick active zone, the $\mathrm{QE}$ at $77 \mathrm{~K}$ reaches $61 \%$ at $\lambda=2 \mu \mathrm{m}$. This study highlights the influence of the p-type doping on the radiometric performances of T2SL detectors. 


\section{REFERENCES}

[1] L. Esaki and R. Tsu. "Superlattice and negative differential conductivity in semiconductors," IBM Journal of Research and Development 14.1 (1970): 61-65.

[2] M.J. Yang, and B.R. Bennet "InAs/GaSb infrared photovoltaic detector at 77K," Electron. Lett. 30 (1994) 1710.

[3] E. Plis, M.N. Kutty, and S. Krishna "Review of passivation techniques for InAs/GaSb strained layer superlattice detectors", Laser \& Photonics Reviews 7 (2011) 1.

[4] R. Rehm, M. Walther, J. Schmitz, J. Fleißner, F. Fuchs, J. Ziegler, W. Cabanski "InAs/GaSb superlattice focal plane arrays for high-resolution thermal imaging," OptoElectron. Rev. 14 (2006) 19.

[5] J. W. Little, S. P. Svensson, W. A. Beck, A. C. Goldberg, S. W. Kennerly, T. Hongsmatip, M. Winn, and P. Uppal, "Thin active region, type II superlattice photodiode arrays : single-pixel and focal plane array characterization," J. Appl. Phys. 101 (2007) 044514.

[6] S.D. Gunapala, D.Z. Ting, C. J. Hill, J. Nguyen, A. Soibel, S. B. Rafol, S.A. Keo, J.M. Mumolo, M.C. Lee, J.K. Liu, B. Yang, and A. Liao, "Demonstration of 1Kx1K long-wave and mid-wave superlattice infrared focal plane arrays," Proc. SPIE 7808 (2010) 780802.

[7] E.K. Huang, S. A. Pour, M.A. Hoang, A. Haddadi, M. Razeghi, and M. Z. Tidrow, "Low irradiance background limited type-II superlattice MWIR M-barrier imager," Optics letters, Vol. 37, No. 11 (2012).

[8] J.-B. Rodriguez, E. Plis, G. Bishop, Y.D. Sharma, H. Kim, and S. Krishna, "nBn structure based on InAs/GaSb type-II strained layer superlattices," Appl. Phys. Lett. 91 (2007) 043514.

[9] B.-M. Nguyen, D. Hoffman, P.-Y. Delaunay and M. Razeghi. "Dark current suppression in type II InAs/GaSb superlattice long wavelength infrared photodiodes with M-structure barrier,” Appl. Phys. Lett. 91 (2007) 163511.

[10] D.Z.Y. Ting, C.J. Hill, A. Soibel, S.A. Keo, J.M. Mumolo, J. Nguyen, and S.D. Gunapala, "A high-performance long wavelength superlattice complementary barrier infrared detector,” Appl. Phys. Lett. 95 (2009) 023508.

[11] B.V. Olson, E.A. Shaner, J.K. Kim, J.F. Klem, S. D. Hawkins, L.M. Murray, J.P. Prineas, M.E. Flatte, and T.F. Boggess, "Time-resolved optical measurements of minority 
carrier recombination in a mid-wave infrared InAsSb alloy and InAs/InAsSb superlattice," Appl. Phys. Lett. 101 (2012) 092109.

[12] T. Schuler-Sandy, S. Myers, B. Klein, N. Gautam, P. Ahirwar, Z.-B. Tian, T. Rotter, G. Balakrishnan, E. Plis, and S. Krishna, "Gallium free type II InAs/InAs $\mathrm{Ab}_{\mathrm{x}}$ superlattice photodetectors,” Appl. Phys. Lett. 101 (2012) 071111.

[13] J.-B. Rodriguez, C. Cervera, and P. Christol, "A type-II superlattice period with a modified InAs to GaSb thickness ratio for midwavelength infrared photodiode performance improvement,” Appl. Phys. Lett. 97 (2010) 251113.

[14] R. Taalat, J.-B. Rodriguez, M. Delmas, and P. Christol "Influence of the period thickness and composition on the electro-optical properties of type-II InAs/GaSb midwave infrared superlattice photodetectors,” J. of Phys. D: Appl. Phys. 47.1 (2014) 015101.

[15] R. Taalat, J.-B. Rodriguez, C. Cervera, I. Ribet-Mohamed, and P. Christol, "Electrical characterizations of asymmetric InAs/GaSb superlattice MWIR photodiodes," Infrared Physics \& Technology 59 (2013) 32-35.

[16] E. Giard, R. Taalat, M. Delmas, J-B. Rodriguez, P. Christol, and I. Ribet-Mohamed, "Radiometric and noise characteristics of InAs-rich T2SL MWIR pin photodiodes," Journal of the European Optical Society-Rapid publications 9 (2014).

[17] D. Hoffman, B.-M. Nguyen, P.-Y. Delaunay, A. Hood, M. Razeghi, and J. Pellegrino, "Beryllium compensation doping of InAs/GaSb infrared superlattice photodiodes," Applied Physics Letters 91 (2007) 143507-143507.

[18] J. Hovel, "Semiconductors and Semimetals", Academic, New York, Vol. 11 (1975) 17-20. 


\section{FIGURE CAPTIONS}

Figure 1 : Schematic view of the SL structure on p-type GaSb substrate.

Figure 2 : Experimental QE spectra for InAs-rich SL photodiodes with different active zone thicknesses at $77 \mathrm{~K}$ and $0 \mathrm{~V}$ bias voltage (samples $\mathrm{A}, \mathrm{B}, \mathrm{C}$ with active thickness equal to 500nm, $1 \mu \mathrm{m}, 4 \mu \mathrm{m}$, respectively). Inset: Experimental $\mathrm{QE}$ at $\lambda=4.5 \mu \mathrm{m}$ versus electric field for these InAs-rich SL photodiodes.

Figure 3 : Comparison between QE spectrum of InAs-rich SL photodiode with $4 \mu \mathrm{m}$ nid active zone and QE spectrum of InAs-rich SL photodiode with $4 \mu \mathrm{m}$ thick p-doped $\left(5 \times 10^{15} \mathrm{~cm}^{-}\right.$

${ }^{3}$ ) active zone (samples C, D respectively), at $77 \mathrm{~K}$ and $0 \mathrm{~V}$ bias voltage. Inset: Experimental $\mathrm{QE}$ at $\lambda=4.5 \mu \mathrm{m}$ versus bias voltage for these two SL photodiodes.

Figure 4 : Experimental (samples D and E) and simulated QE spectra of p-type doped InAsrich photodiodes with different active zone thicknesses.

Figure 5 : Experimental and simulated QE spectra for three different T2SL designs with $1 \mu \mathrm{m}$ active zone thickness at $77 \mathrm{~K}$ and $0 \mathrm{~V}$ bias voltage.

\section{TABLE CAPTIONS}

Table 1 : SL photodiode sample characteristics. 


\section{TABLES}

\begin{tabular}{|c|c|c|c|c|c|c|c|}
\hline Sample & $\mathrm{A}$ & $\mathrm{B}$ & $\mathrm{C}$ & $\mathrm{D}$ & $\mathrm{E}$ & $\mathrm{F}$ & $\mathrm{G}$ \\
\hline Design & InAs-rich & InAs-rich & InAs-rich & InAs-rich & InAs-rich & GaSb-rich & Symmetric \\
ML GaSb) & $7 / 4$ & $7 / 4$ & $7 / 4$ & $7 / 4$ & $7 / 4$ & $10 / 19$ & $10 / 10$ \\
\hline Active zone & nid & nid & nid & p-type & p-type & nid & nid \\
doping & $\mathrm{n}$ residual & $\mathrm{n}$ residual & $\mathrm{n}$ residual & & & $\mathrm{p}$ residual & p residual \\
\hline Active zone & $500 \mathrm{~nm}$ & $1 \mu \mathrm{m}$ & $4 \mu \mathrm{m}$ & $4 \mu \mathrm{m}$ & $500 \mathrm{~nm}$ & $1 \mu \mathrm{m}$ & $1 \mu \mathrm{m}$ \\
thickness & & & & & & & \\
\hline
\end{tabular}

Table 1

E. Giard et al.

Influence of the p-type doping on the radiometric performances of MWIR InAs/GaSb superlattice photodiodes 


\section{FIGURES}

\begin{tabular}{|c|}
\hline cap $\operatorname{InAs~n^{+}}=1.10^{18} \mathrm{~cm}^{-3} \quad(20 \mathrm{~nm})$ \\
\hline $\mathbf{n}^{+}(\mathrm{Te}) \quad$ SL $(60 \mathrm{~nm})$ \\
\hline active zone SL n.i.d \\
\hline $\mathbf{p}^{+}(\mathrm{Be}) \quad$ SL $(60 \mathrm{~nm})$ \\
\hline GaSb p ${ }^{+}=1.10^{18} \mathrm{~cm}^{-3}(200 \mathrm{~nm})$ \\
\hline GaSb (p) substrate (2") \\
\hline
\end{tabular}

Figure 1

E. Giard et al.

Influence of the p-type doping on the radiometric performances of MWIR InAs/GaSb superlattice photodiodes 


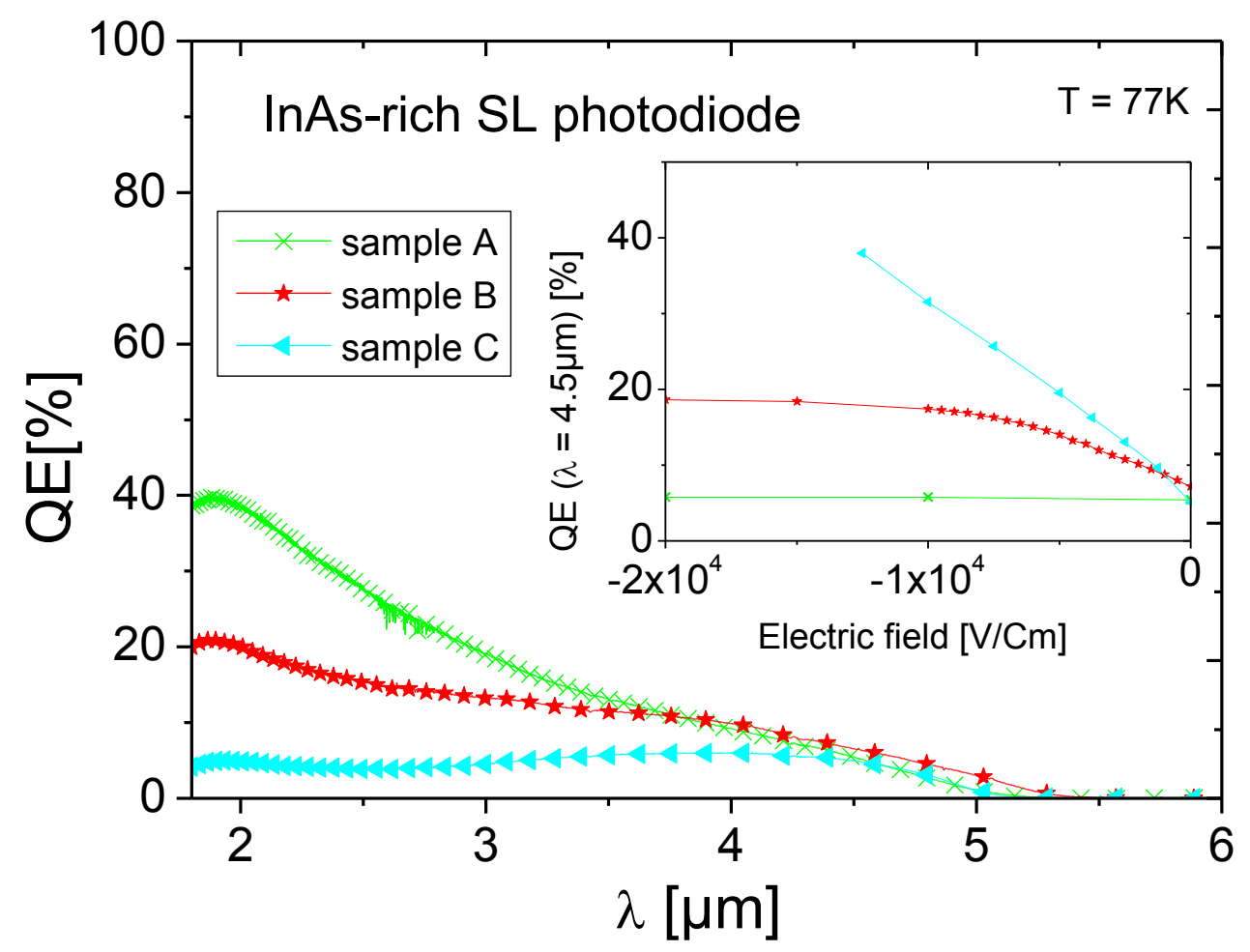

Figure 2

E. Giard et al.

Influence of the p-type doping on the radiometric performances of MWIR InAs/GaSb superlattice photodiodes 


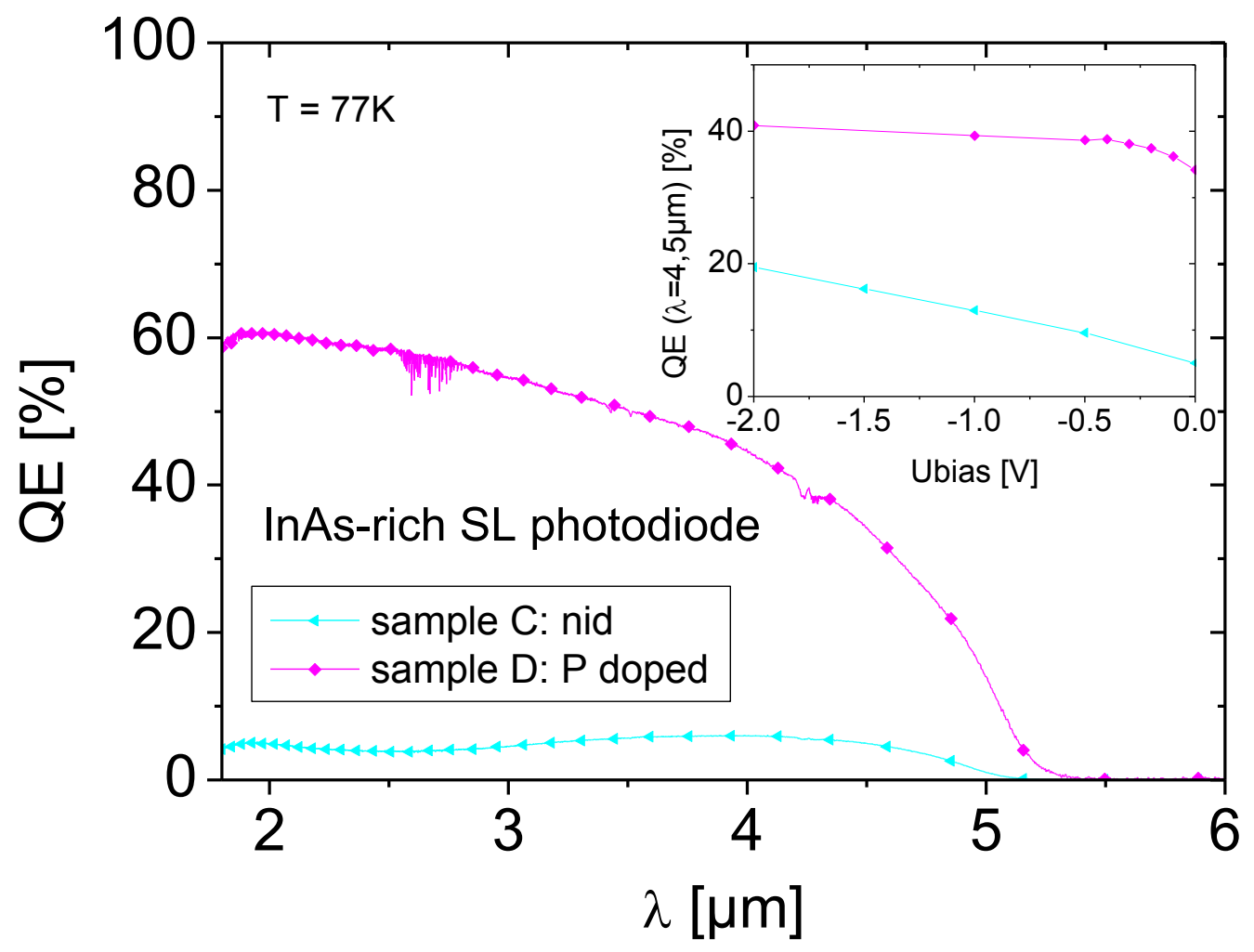

Figure 3

E. Giard et al.

Influence of the p-type doping on the radiometric performances of MWIR InAs/GaSb superlattice photodiodes 


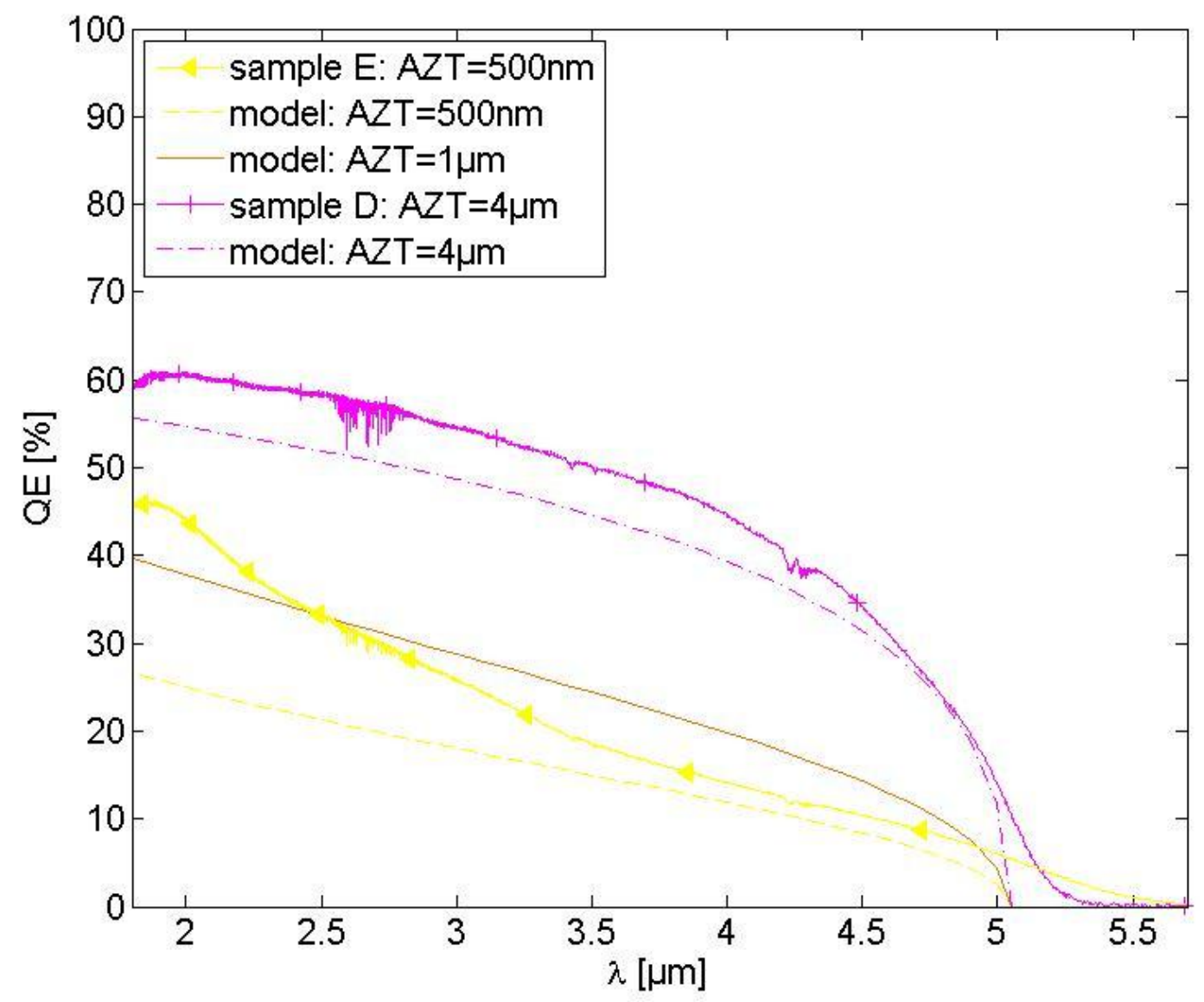

Figure 4

E. Giard et al.

Influence of the p-type doping on the radiometric performances of MWIR InAs/GaSb superlattice photodiodes 


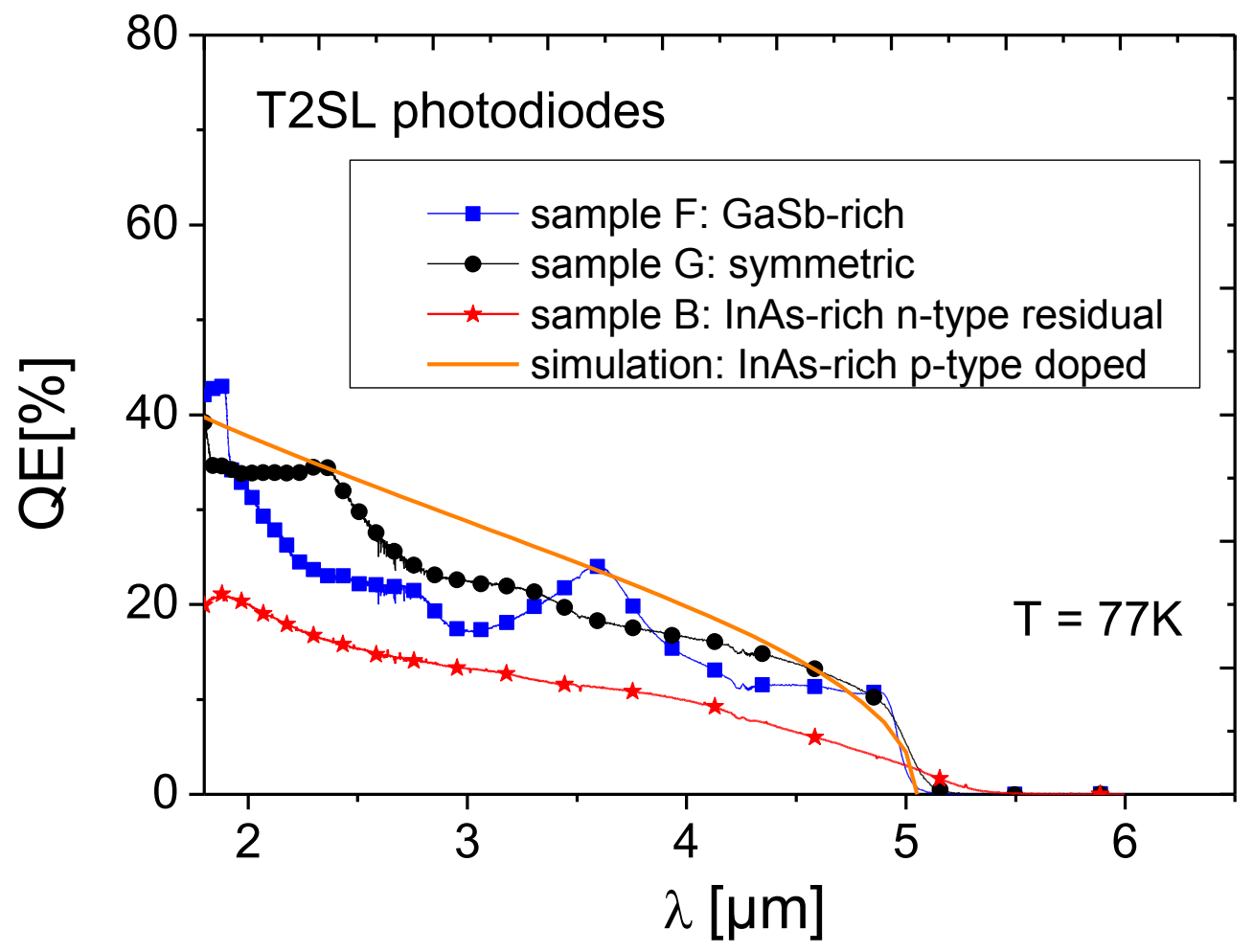

Figure 5

E. Giard et al.

Influence of the p-type doping on the radiometric performances of MWIR InAs/GaSb superlattice photodiodes 